\title{
Autologus Stem Cell Transplantation for Cancers: India: 2017
}

\section{Shreeniwas Shilawant Raut ${ }^{*}$}

Gujarat Cancer and Research Institute, B.J. Medical College, Ahmedabad, 380016, India

*Corresponding author: Shreeniwas Shilawant Raut, MD.DM Gujarat Cancer and Research Institute, B.J. Medical College, Ahmedabad, 380016 , India, Tel: +91 9099407702; E-mail: shriniatbj@yahoo.co.in

Received date: Jan 27, 2017; Accepted date: April 13, 2017; Publication date: April 22, 2017

Copyright: (C) 2017 Raut SS. This is an open-access article distributed under the terms of the Creative Commons Attribution License, which permits unrestricted use, distribution, and reproduction in any medium, provided the original author and source are credited.

\begin{abstract}
India is a well-known destination for health tourism including hematopoietic stem cell transplantation for various cancers like multiple myeloma, Hodgkin and non-hodgkin lymphoma. Hematopoietic stem cell transplant is cheaper in India as compared to developed countries and there is a huge cost difference. Here, the numbers of stem cell transplant centres and transplant activity are increasing. In this paper, we summarise present status of autologus stem cell transplant for various cancers in India including the basics of autologus stem cell transplant procedure and reported statistics. This will add to scarcely reported literature in this topic as well as encourage the Indian stem cell transplant activity.
\end{abstract}

Keywords: Metabolism; Graft venous host; Immunodeficiency; Stem cell transplantation

\section{Introduction}

Preclinical studies in animals showed that stem cell transplantation (SCT) can restore blood production. This created a new highway of curative therapy in many malignant and nonmalignant diseases (errors of inborn metabolism, congenital immunodeficiency and hemoglobinopathies). High dose chemotherapy (HDCT) and radiotherapy (RT) shows the steep dose response curves. This dose exceeds the normal tolerance of bone marrow. The fatal bone marrow aplasia (BMA) secondary to HDCT, if restored through autologous stem cells, it is called as autologous stem cell transplantation (ASCT). Hence the principle of ASCT is "more the better". ASCT depends on HDCT for eradication of malignancy as compared to allogenic transplant (allo SCT) which has additional graft versus host effect (GVHE) to counteract the malignancy. ASCT is also free of significant long term immunosuppression and delayed immune reconstitution. The chemotherapy and radiation therapy are regimen specific to particular diseases [1-8].

\section{What are stem cells?}

Hematopoietic stem cells (HPSC) identified by flow - cytometry detectable expression of CD34. CD34 + cells present in small quantities in bone marrow $(0.5-1 \%)$ and in tiny quantities $(0.05-0.1 \%)$ in circulating blood. Hematopoietic stem cells (HSC) also express human leukocyte antigen (HLA) antigens, but do not carry ABO blood group antigens. These pluripotent stem cells replenish themselves as well as differentiate in to multipotent progenitor cells and finally irreversibly form specific lineage-restricted cells. Age is a limitation factor to allogenic SCT, cut off being 55 years. This led to the development of the concept of ASCT. Phases of ASCT include Collection, Cryopreservation, HDCT, Thawing, Infusion of stem cells and Supportive care.

\section{Pretransplant evaluation}

Evaluation of disease status, Complete blood counts, Biochemistry, HIV, Hepatitis B and C, Pulmonary function test, 2 D Echo.

\section{Indications}

Indications according to worldwide reporting with descending order are multiple myeloma (50-55\%), non-Hodgkin lymphoma (20-25\%), Hodgkin lymphoma (8-9\%), light chain amyloidosis $(0.5 \%)$, and acute myeloid leukemia $(0.5 \%)$. Especially acute promyelocytic leukemia, acute lymphoblastic leukemia $(0.1 \%)$, chronic lymphoblastic leukemia(0.1\%), germ cell tumour (1\%). Unsuitable patients for ASCT are those with Karnofsky score $<70, \mathrm{LVEF}<40 \%$, Compromised FEV1, $\mathrm{DLCO}<40 \%$ of predicted normal, Creatinine $>3 \mathrm{mg} / \mathrm{dl}$, heavily pretreated patients, and Chemorefractory patients.

\section{Collection}

Hematopoietic progenitor stem cells (HPC) for ASCT have 2 sources, bone marrow (BM) and peripheral blood (PBSC). After collection the stem cells are can be preserved at 2 to $4^{\circ} \mathrm{C}$ for use within 7 days or it can be suspended in a balanced salt solution with cryoprotectant (e.g. DMSO, dimethyl sulfoxide) in liquid nitrogen. For bone marrow (BM) collection usually the volume is 10 to $15 \mathrm{ml} / \mathrm{kg}$ patient weight (1000 ml approx). Minimum dose of stem cells should be 2 million CD $34+$ cells $/ \mathrm{kg}$ recipient body weight ( $>4$ to 6 million cells/kg being the optimal). Mobilization of HPC is done either by cytokine only strategy (G-CSF) or with chemo-mobilization (low dose cyclophosphamide). Plerixafor is also used that works through disrupting the bonding of chemoreceptor type 4 and stromal derived factor to the marrow stromal cells and HPC. Mobilization is 4 fold increase of circulating progenitors. This term was used first in 1977 in experimental administration of endotoxin in healthy subjects. Growth factors alone or that after chemotherapy is used for collecting stem cells. According to CIBMTR reports, now virtually all ASCT are performed with mobilized hematopoietic stem cells. Mobilization with chemotherapy achieves antitumour activity as well. 
Page 2 of 8

\section{Mobilizing agents}

These agents are used to mobilize stem cells from bone marrow to peripheral blood for ease of collection. The doses are as followsFilgrastim is $10 \mathrm{mcg} / \mathrm{kg} /$ day SC at least 4 days prior to collection. Lenograstim is glycosylated form of GCSF yet to be standardized in practice. Sargramostim (GM CSF) is rarely used now. Cyclophosphamide $1-5 \mathrm{gm} / \mathrm{m}^{2}$. It is more used as a part of conditioning regimen rather than mobilization purpose. Plerixafor is a CXCR4 antagonist reducing the binding and chemotaxis of HSC to $\mathrm{BM}$ stroma. After 4 days of filgrastim and 11 hours prior to apheresis $-0.24 \mathrm{mg} / \mathrm{kg} \mathrm{SC}$ qDay ( $\max 40 \mathrm{mg}$ per day) for up to 4 consecutive days.

\section{Ancestim (recombinant human stem cell factor)}

It is a soluble surface molecule on bone marrow stromal cells. It is used in conjunction with filgrastim $-20 \mathrm{mcg} / \mathrm{kg} / \mathrm{day}$ SC.

\section{Insertion of catheter}

A double lumen catheter is inserted in juglar or sublclavian vein, which serves both for collection of stem cells and intravenous access for transplantation. Table 1 Shows most commonly used conditioning regimens for various diseases. E.g. for multiple myeloma it is single agent melphalan, for lymphoma it is BEAM (BCNU, etoposide, Ara C, Melphalan), for AML it is $\mathrm{BuCy}$ ( Busulphan, Cyclophosphamide). Isolation: The patient is nursed in an isolated environment till the newly infused normal marrow cells engraft and start functioning. This takes 3-4 weeks. Table 2 Shows various precautions for a hematopoietic stem cell marrow transplant unit. Isolation and asepsis are crucial in the process [9].

\begin{tabular}{|l|l|}
\hline MM & Melphalan \\
\hline Iymphoma & BEAM, CBV \\
\hline AML & BU, CY \\
\hline Neuroblastoma & Busulfan + melphalan \\
\hline Wilm tumour & no standard \\
\hline Ewing sarcoma & no standard \\
\hline Germ cell tumour & TICE \\
\hline
\end{tabular}

Table 1: Most Common Conditioning Regimens for Different Diseases

\begin{tabular}{|l|}
\hline No sick visitors \\
\hline Hand washing \\
\hline Mask (optional) \\
\hline Gowns( optional) \\
\hline Gloves (optional) \\
\hline Shoe coverings(optional) \\
\hline HEPA filter and laminar flow are level 3 recommendations. \\
\hline
\end{tabular}

Table 2: Safety Precautions For Both Staff And Visitors [9]

\begin{tabular}{|l|}
\hline Day of transplant \\
\hline Fever \\
\hline Chills \\
\hline Hypotension \\
\hline Chest tightness \\
\hline Cough \\
\hline During engraftment ( weeks 1 to 4 ) \\
\hline Infections: bacterial, viral, fungal \\
\hline Nausea and vomiting \\
\hline Fluid and electrolyte disturbance \\
\hline Mucositis \\
\hline Malnutrition \\
\hline Bleeding and bruising \\
\hline Need of blood components \\
\hline Diffuse alveolar hemorrhage \\
\hline Hepatic venoocclusive disease \\
\hline Post-transplant (months to years) \\
\hline Relapse of disease \\
\hline Leukemia \\
\hline Myelodisplastic syndrome \\
\hline Interstitial pneumonitis \\
\hline Hemorrhagic cystitis \\
\hline Toxicity of the procedure and supportive care \\
\hline
\end{tabular}

Table 3: Complications of Autologus transplantation Day of Transplant

Table 3 Enumerates the toxicity of HSCT which induced by cytopenia and organ damage through HDCT. Oral mucositis, Diarrhoea, pain, infections, nausea, vomiting, alopecia, Anorexia, rash are usual. Cytopenias recover within 3 weeks. Further growth factor support (G CSF) enhances recovery by 4 days. Packed red cells (PRBC) and platelet transfusion (SDP preferably) are required to counteract the cytopenias. Transfusion associated graft versus host disease (GVHD) is prevented by irradiating all the blood products before transfusion. Stem cells are not to be irradiated. Major infections are gram negative bacteria, gram positive bacteria, clostridia, herpes and fungi in descending order. Prophylactic antibiotics, antivirals, antifungals, growth factors are recommended.

Hepatic veno-occlusiove disease (hepatomegaly, jaundice, fluid retention) and idiopathic pneumonia syndrome, acute respiratory distress can also occur. Transplant related mortality (TRM) is usually $<3 \%$, ideally it should be $0 \%$. Relapses are more common in ASCT than allo SCT. Causes of death are primary disease (65-69\%), infections (6-8\%), organ failure (3-4\%), secondary malignancies (1-2\%) and other (16-18\%) 


\section{Infection prophylaxis}

It takes one to 2 years for immunological recovery after HSCT. Usually neutrophil engraftment takes within 3 weeks in ASCT. Isolation is done till day +30 post transplant. Oral cavity, skin and perianal hygiene is to be maintained.

\section{Bacterial prophylaxis}

It includes Ciprofloxacin $500-750$ PO BID or alternatively ceftriaxone $2 \mathrm{gm}$ IV. Other newer fluoroquinolones are not active against polyoma virus.

\section{Fungal prophylaxis}

It usually includes Fluconazole or Posaconazole or Voriconazole. Fluconazole decreases candida infection but not Aspergillosis. Posaconazole may be preferred in allo SCT where the risk of fungal infection is more.

\section{Viral prophylaxis}

It includes Acyclovir for HSV Prophylactic Ganciclovir for CMV is controversial in ASCT. In allo SCT, post-transplant if CMV PCR is positive one can start treatment with Ganciclovir before clinical manifestations.

\section{Parasite and Pneumocystis jirovaci prophylaxis}

We use oral Albendazole $400 \mathrm{mg}$ single dose on day 9 and oral Cotrimoxazol DS alternate day from day -14 to day -2 and then from engraftment till 6 months or till GVHD resolves whichever is later.

\section{Transfusion strategy}

SDP transfusion if Platelet count is $<20,000 /$ c.mm and Packed red cells if Hemoglobin is $<8.0 \mathrm{gm}$ is to be supported. All the blood products should be irradiated to prevent graft versus host disease.

\section{Stem cell transplantation}

Actual process of autologous stem cell infusion is same as blood transfusion. Hence the precautions are same as that of regular blood transfusion. Mannitol and diuretics are used when hemolysis is suspected after stem cell transfusion (suspected with reddish urine or decreased urine output).

\section{Recovery (supportive care)}

Peritransplantation: Indications for various blood products are as follows: RBC, platelet, and plasma indications for transfusion do not differ significantly from non-HSPC patients. RBC "threshold" hemoglobin 7 or $8 \mathrm{~g} / \mathrm{dL}$ (higher in cardiac patients). Platelet threshold commonly $10,000 / \mu \mathrm{L}$ for prophylactic transfusion, 50,000 for bleeding patients. FFP indications are not well-established (as is true elsewhere); FFP is not widely used in HPC transplants.

\section{Post-transplant}

Irradiated products are used (probably forever) and Leukocytereduced products used for HLA immunization prevention.

\section{Engraftment}

The date of neutrophil recovery is scored as the first of 3 consecutive days with ANC $0.5 \times 109 / \mathrm{L}$ or greater and unsupported platelet count $\geq 20 \times 109 / \mathrm{L}$ on 3 consecutive days.

\section{Multiple myeloma}

Multiple myeloma (MM) is incurable. ASCT has proved to prolong both event free survival (EFS) and overall survival (OS). There are 3 transplant strategies in MM for ASCT, upfront ASCT, delayed ASCT and ASCT on relapse. The Intergroup Francophone myeloma (IFM) and Medical Research Council trials showed significant increased OS, EFS and complete remission (CR) rates with ASCT than conventional dose chemotherapy (CDCT). For a young patient ( $<65$ years) Melphalan $200 \mathrm{mg} / \mathrm{m}^{2}$ is the standard conditioning regimen for MM. Elderly patients usually receive $100-140 \mathrm{mg} / \mathrm{m}^{2}$ Melphalan (preferably $140 \mathrm{mg} / \mathrm{m}^{2}$ ). As the stem cells can be stored at 2 to $4^{\circ} \mathrm{C}$ for up to 5 days, ASCT in MM may be done without use of DMSO. Also during thawing, residual DMSO can cause histamine release syndrome, hypotension, abdominal pain and renal failure. Some patients who are not in very good partial response (VGPR) at the time of first ASCT can be offered tandem ASCT (second ASCT within 6 months), with prior storage of adequate stem cells using DMSO. This approach was proved to increase OS and EFS at 7 years in IFM94 trial. Delaying ASCT at the time of relapse is not as effective as the upfront consolidation ASCT protocol. High risk biology e.g. $\mathrm{t}$ (4:14), del (17p) or high $\beta 2$ microglobin predict poor prognosis even with ASCT. When patient is not in VGPR at the time of stem cell collection, it is practice to use intermediate dose cyclophosphamide or plerixafor based mobilization. Melphalan, overuse of Lenalidomide and RT are to be avoided if ASCT is in consideration. The optimum dose of CD 34 cells in collection should be 6 to 10 million.Post transplantation maintenance of thalidomide, lenalidomide and bortezomib have demonstrated superior progression free survivals (PFS), but the risks of secondary malignancies should be explained. Second transplants are beneficial to patients who have PFS $>36$ months after first ASCT. Third ASCT are usually not beneficial [10-15].

\section{Future directions in myeloma ASCT}

Novel conditioning regimens, Pet CT scan and minimal residual disease (MRD) are being increasingly incorporated to enhance the ASCT outcomes of MM.

\section{Landmark trials in myeloma ASCT}

Child et al. [10] reported CR rate of $44 \%$ with Melphalan 200 $\mathrm{mg} / \mathrm{m} 2$ as compared to $8 \%$ with chemotherapy on population less than 65 years of age with MM. Both OS and EFS were superior for ASCT than chemotherapy.

\section{Lymphoid malignancies}

Relapsed Hodgkin and relapsed, aggressive non Hodgkin lymphoma demonstrate $45 \%$ cure rate with ASCT. In heavily pretreated patients cytokine only based mobilization may be inadequate and chemotherapy or plerixafor based mobilizations are preferred. CBV and BEAM are standard conditioning regimens for ASCT in lymphoma. Radioimmunotherapy based conditioning regimens are not favoured in various studies [16-23]. 


\section{Follicular lymphoma, first remission}

The routine use of upfront ASCT consolidation in follicular lymphoma is not recommended in the rituximab era because though ASCT may offer better event free of progression free survival, it does not associated with better overall survival rather it is associated with increased TRM and greater percentage of secondary malignancies [16]

\section{Follicular lymphoma (FL), relapsed}

ASCT is reserved for chemotherapy sensitive, relapsed FL in patients who are not candidates for allogenic transplantation. CIBMTR-2004 retrospective data shows better overall and event free survival with purged ASCT (62\% vs. 55\%).

\section{Transformed FL}

ASCT is indicated for transformed FL with nonbulky and chemosensitive disease.

\section{Mantle cell lymphoma (MCL)}

ASCT is recommended for chemosensitive, relapsed MCL patients, who are candidates for allogenic HSCT. Hermine et al. [19] demonstrated near doubled EFS (84 months vs. 49 months) with marked OS advantage with R-DHAP induction ASCT. Rituximab and addition of Cytarabine in induction improved the OS [20].

\section{Waldenstrom macroglobulinemia(WM)}

ASCT is indicated in relapsed chemosensitive WM patients who have received 2 or 3 different therapies.

\section{Marginal zone lymphoma (MZL)}

In relapsed, chemosensitive MZL, ASCT is recommended.

\section{Chronic lymphocytic leukemia (CLL)/small lymphocytic lymphoma (SLL)}

ASCT is not beneficial in CLL/SLL.

\section{Diffuse large B cell lymphoma (DLBCL), first remission}

Upfront ASCT is not indicated in DLBCL.

\section{DLBCL, relapsed disease}

ASCT is standard treatment for relapsed, chemosensitive DLBCL. CORAL study (2010) established the role of ASCT (EFS 53\%) for relapsed DLBCL after RICE and RDHAP based salvage [23].

\section{Burkitt lymphoma (BL)}

ASCT is not required in BL in first $\mathrm{CR}$, but in relapsed chemosensitive BL gives 3 year PFS of $30 \%$.

\section{Hodgkin lymphoma (HL), relapsed or primary refractory}

ASCT is curative and standard procedure in relapsed chemosensitive HL as well as primary refractory cases. CIBMTR (2001, 1999) data shows that patients in second CR have better outcomes and upto $40 \%$ of primary refractory patients can be salvaged by ASCT [22].

\section{T cell lymphoma (TCL)}

ASCT can be considered for relapsed, chemosensitive TCL patients who are not candidates for allo SCT. Tumour cell contamination in Autograft: In vivo (rituximab based) or ex vivo (by monoclonal antibodies, CD34+ selection) purging have not been successful till date to increase the survival by decreasing the tumour cell contamination in autograft.

\section{Post-transplant maintenance therapies for lymphoma}

Post-transplant rituximab maintenance has shown to increase the PFS in FL but not in DLBCL.

\section{PET scan in ASCT}

Pet negative state before or after ASCT is predictive of improved ASCT outcomes.

\section{Rarer plasma cell dyscrasias}

High dose therapy with melphalan has been effective in Light chain amylodosis, light chain deposition disease, and POEMS syndrome but randomized clinical trials are yet awaited.

\section{Acute myeloid leukemia (AML)}

Patients of AML with favourable or intermediate risk cytogenics can be considered for ASCT after induction therapy when suitable donor is not available.

\section{Acute lymphoid leukemia (ALL)}

Routine ASCT in ALL in first line as consolidation or maintenance or in relapsed patients is not recommended in current scenario. Some older studies have demonstrated similar EFS with ASCT as compared to allo SCT in selected patients. However, Philadelphia chromosome positive patients receiving tyrosine kinase inhibitors with chemotherapy can be considered for ASCT when suitable donors are not available.

\section{Germ cell tumour (GCT)}

ASCT is recommended in high risk GCT who are relapsed after or refractory to first line chemotherapy.

\section{Late complications of ASCT}

ASCT decreases the life expectancy and have increased risk for opportunistic infections, iron overload, endocrine disturbances, osteoporosis and second malignancies.

\section{Preventive maintenance after transplant}

It is also recommended to follow healthy practices i.e. not using tobacco and alcohol, having healthy foods, exercise and regular sunscreen use.

Blood tests: Annual complete blood count (CBC), blood glucose level, serum lipid levels, liver function tests, renal function tests, thyroid hormone levels.

Dental: To maintain good oral health and having routine dental examinations after transplant. One can resume routine dental 
cleanings and treatments after 6 months of ASCT. One should avoid routine dental treatment if he had an ASCT less than 6 months before. This precaution does not prevent you from receiving dental treatment that is necessary. If dental treatment is medically necessary, it is important to take antibiotics before the treatment for preventing infections. Dentist should know that patient has had a transplant. The risk for osteonecrosis persists for many years, even after treatment with the bisphosphonate drug has been stopped. Children who had a transplant before the age of 10 should have a Panoramic dental x-ray taken approximately every year to assess tooth development and eruption.

Eyes: Evaluation is done for cataract annually.

Lungs: Pulmonary function tests one year and five years after transplant, or annually if respiratory symptoms.

Bones: Bone density test / DEXA scan at one year post-transplant, to be repeated annually if the initial test shows decreased density. Patients taking prednisone should do a DEXA scan annually.

Colon: Test for blood in the stool every year and a colonoscopy at age 50 years.

Females: Annual Pap smear, breast examination and mammogram (after age 45).

\section{Patients with CML: BCR/ABL test annually.}

Children: Every 6 months height should be measured. Growth hormone levels should be tested every year until age of 16 years. Pulmonary function tests should be done annually after age 6 . The transplant related treatments with chemo-radiation increase the risk of second cancers e.g. skin cancer, head and neck cancer, breast cancer, thyroid cancer (papillary thyroid carcinoma), and brain cancers (astrocytomas). The risk of hepatocellular carcinoma is increased in patients with hepatitis $\mathrm{C}$ infection. We recommend that all patients should follow a healthy lifestyle. Exercise, walking and weight-bearing for 20-60 minutes every day for stamina and to prevent bone loss; a healthy, balanced diet with five daily servings of fruits and vegetables; vitamin and mineral supplements of calcium and vitamin $\mathrm{D}$, to prevent bone loss when the diet doesn't contain recommended $1500 \mathrm{mg}$ of calcium and 800 i.u. of vitamin D per day; avoiding exposure to direct sunlight by using a hat, long-sleeves and sunscreen; regular handwash.

\section{Indian data}

Most common indication for ASCT in India is MM which comprises half population of ASCT cases, lymphoma being the next common. There are 52 HSCT centres in india. Though the population of India is several times more than USA, the HSCT activity in india is 10 times less than USA. This is the failure to deliver standard of care curative treatment strategies in cancer. But the graphical representation of estimated HSCT activity in Figure 1 and Figure 2 shows that the HSCT activity in India in exponentially increasing and hopefully soon the unmet need will be covered. In total 52 centers across all over India overall 10381 stem cell transplantations were reported since 1983 to 2015 . Out of these 6240 were allo SCT whereas 4141 were ASCT. The graph shows gradual but persistent increase in the SCT activity. In initial decade the numbers counted less than 10 per year but presently it has reached more than a thousand per year. Sixty percent of this counts allogenic and $40 \%$ is autologous SCT activity.

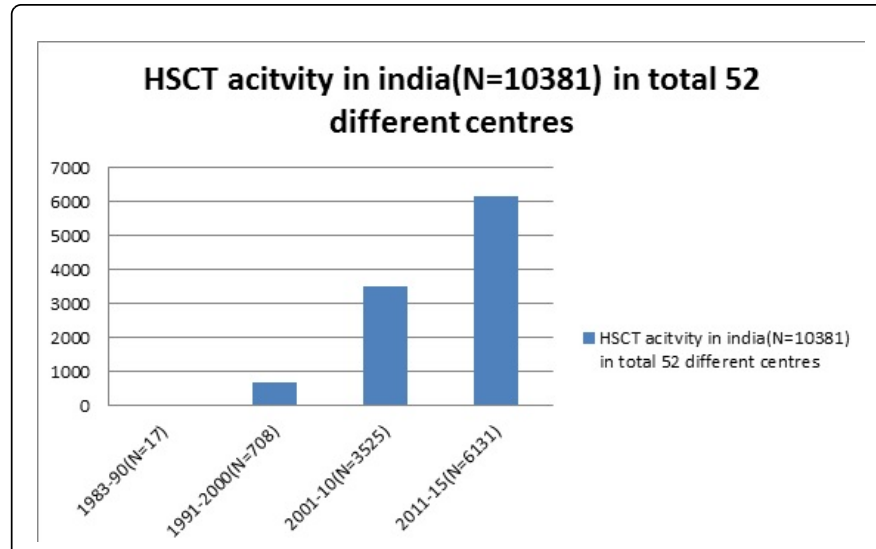

Figure 1: Yearwise growth of overall hematopoetic stem cell transplant activity in India

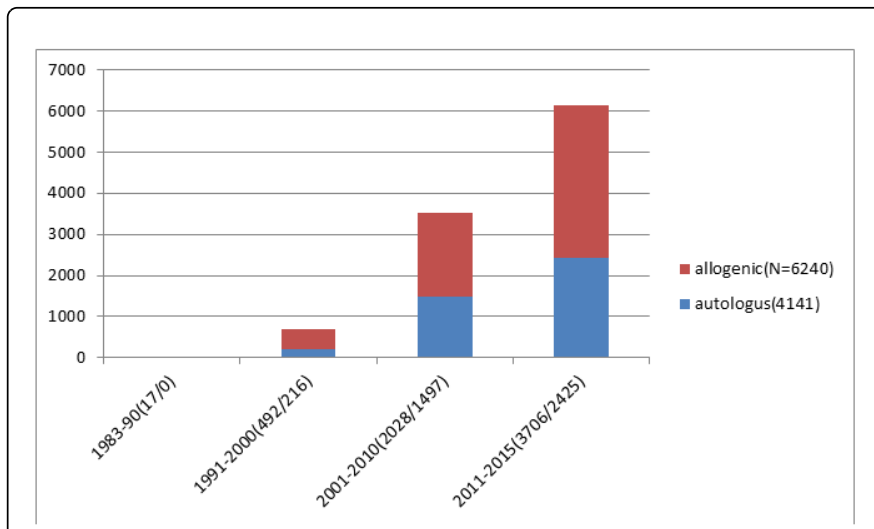

Figure 2: Yearwise growth in autologus and allogenic stem cell transplant activity in India.

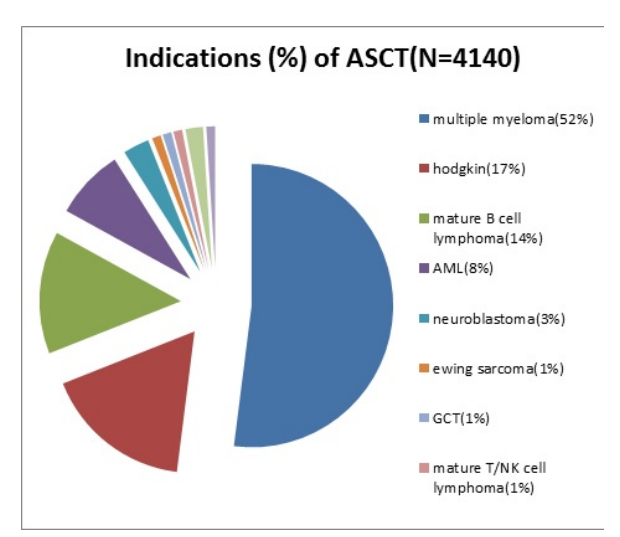

Figure 3: Percentage representation of various diseases undergoing autologous hematopoetic stem cell transplant in India.

Out of 4140 autologus transplants, 52\% were multiple myeloma, $14 \%$ were mature B cell lymphoma, 17\% were Hodgkin lymphoma. 
Page 6 of 8

\section{Cost of ASCT in India}

ASCT is not an expensive mode of therapy in developing countries as compared to west but it is still unaffordable to most of Indian patients. It costs 5 to 10 lakh. This cost is 20 times more in developed countries. Therefore india has a good scope and potential for medical tourism in HSCT. Majority of the bacterial infections documented from western world has dominance of gram positive organisms but in India, gram negative organisms dominate the culture reports. Also, there are a few reports from India showing good outcome of HSCT even in compromised infrastructure e.g. without HEPA filters. The trend of "ASCT with bone marrow proper" collection has been shifted to "peripheral blood stem cell based ASCT" without compromising efficacy. Still the major hurdle seems to be financial problems and lack of awareness about HSCT leading to less referral for HSCT in Indian medical practice. Provided the curative potential of HSCT even in relapsed/ refractory cases the serious efforts and awareness should be increased along with the formal training of the procedure (Figure 3).

\section{Future}

Current national capacity is suboptimal to meet the needs for India's population (with an estimated incidence of 1,000,000 new cancer patients/year). Existing centers need to focus on the development of regimen/ strategies tailored to our needs. For instance, cancers like
MM are diagnosed very early in our population. They are in the most productive phase of their lives and are fit to tolerate dose intensive therapy. Hence they should be subject to strategies that lead to a curative outcome. HSCT is the only curative mode of treatment for several cancers. Gene therapy is yet to standardize its application with HSCT.

\section{Medical Tourism in India}

By 2020 India is projected to a growth about 8 billion dollars in medical tourism. India is preferred medical hub by UK and USA due to low cost of treatment while Bangladesh and Afghanistan patients prefer Indian healthcare due to poor infrastructure in respective countries and close proximity to India. Russia and Middle East country patients contribute in next rank. Major destinations in India include Chennai, Kolkata, Mumbai, Hyderabad, and Delhi-NCR. Indian healthcare is advancing to international qualities and patients all over the world face lesser language barrier day by day. There are approximately 25 JCI accredited hospitals in India. Visa on arrival scheme allows foreign patients to stay about a month which decreases the difficulty of foreign patients taking treatment in India. Some hospitals also have hired the facility of language translators to facilitate foreign patients.

\section{Advantages}

No need to identify donor if peripheral blood is uninvolved by tumour at the time of collection

No immunosuppression, less risk of infections

No GVHD

Dose intensive therapy can be used for older patients( usually up to age 70)

Low early treatment related mortality $(2 \%-5 \%)$

Disadvantages

Not feasible if peripheral blood stem cells/ marrow involved

Possible marrow injury leading to late myelodysplasia ( either from prior chemotherapy or transplant regimen)

No graft versus tumour effect

Not all patients can be mobilized to give adequate cell doses for reconstitution.

Table 4: Advantages And Disadvantages Of Autologous Stem Cell Transplantation (ASCT)

\begin{tabular}{|l|l|l|l|}
\hline Year and author & Analysis & Institution & Contribution \\
\hline $\begin{array}{l}\text { 2017, prinja et al. } \\
{[23]}\end{array}$ & cost effectiveness of ASCT & PGI Chandigarh & $\begin{array}{l}\text { Cost effectiveness of ASCT improved with early detection and initiation of } \\
\text { treatment. }\end{array}$ \\
\hline $\begin{array}{l}\text { 2016, Raut et al. } \\
{[24]}\end{array}$ & ASCT in HD & GCRI Ahmedabad & DFS 65\% and OS 70\% \\
\hline $\begin{array}{l}2016, \text { Kumar et al. } \\
{[24]}\end{array}$ & $\begin{array}{l}\text { ASCT for myeloma: long term } \\
\text { results }\end{array}$ & AllMS new Delhi & $\begin{array}{l}\text { CR following ASCT associated with good long term outcome. PFS:32 months, } \\
\text { OS: } 85 \text { months }\end{array}$ \\
\hline $\begin{array}{l}2015, \text { Raut et al. } \\
{[25]}\end{array}$ & $\begin{array}{l}\text { safety of Eltrombopag in post HSCT } \\
\text { thrombocytopenia }\end{array}$ & $\begin{array}{l}\text { GCRI Ahmedabad } \\
\text { 2015, Shah et al. } \\
{[5]}\end{array}$ & $\begin{array}{l}\text { data from western India } \\
\text { appears efficacious and offers transfusion independence. }\end{array}$ \\
\hline
\end{tabular}




\begin{tabular}{|c|c|c|c|}
\hline $\begin{array}{l}\text { 2014, Shah et al. } \\
{[26]}\end{array}$ & $\begin{array}{l}\text { ASCT in MM in Non university } \\
\text { hospital of developing country }\end{array}$ & $\begin{array}{l}\text { Apollo hospital, } \\
\text { Gandhinagar }\end{array}$ & ASCT feasible in Non university hospital \\
\hline $\begin{array}{l}\text { 2014, sharma et al. } \\
\text { [3] }\end{array}$ & cost of HSCT in India & $\begin{array}{l}\text { BLK superspeciality } \\
\text { hospital New Delhi }\end{array}$ & ASCT cost12500 USD(10331-39367) \\
\hline 2014, Kumar [27] & CR after ASCT in MM & AlIMS New Delhi & $\begin{array}{l}\text { those who receive one line of induction therapy before transplant have superior } \\
\text { outcome, }\end{array}$ \\
\hline $\begin{array}{l}\text { 2013, Kayal et al. } \\
{[14]}\end{array}$ & $\begin{array}{l}\text { ASCT using non cryopreserved } \\
\text { peripheral blood stem cells }\end{array}$ & AlIMS New Delhi & Noncryopreserved PBSC is simple, effective and safe. \\
\hline $\begin{array}{l}2012 \text {, } \\
\text { Mukhopadhyay et } \\
\text { al. [7] }\end{array}$ & Data from Eastern India & NCRI Kolkata & ASCT cost 3-4 lakhs \\
\hline $\begin{array}{l}\text { 2010, Kumar et al. } \\
{[18]}\end{array}$ & ASCT for $\mathrm{HL}$ and $\mathrm{NHL}$ & AllMS New Delhi & $\begin{array}{l}\text { pretransplant chemosensitive disease and } \mathrm{CR} \text { after transplant had better } \\
\text { survival }\end{array}$ \\
\hline
\end{tabular}

Table 5: Summarizing latest scientific reports with their inputs in ASCT activity in India

\section{Compliance with Ethical Standards}

We didnot violate any of the ethical concerns in this study.

\section{Funding}

This study was not funded.

\section{Conflict of Interest}

Author declared no conflicts of interest in any form. All procedures performed in studies involving human participants were in accordance with the ethical standards of the institutional and/or national research committee and with the 1964 Helsinki declaration and its later amendments or comparable ethical standards.

\section{References}

1. Chandy M (2008) Stem cell transplantation in India. Bone Marrow Transplant 42: 81-84.

2. Kumar R (2002) Stem cell transplantation: Indian perspective. J Ind Acad Clin Med 3: 182-188.

3. Sharma KS, Choudhary D, Gupta N, Dhamija M, Khandelwal V, et al. (2014) Cost of hematopoietic stem cell transplantation in India. Mediterr J Hematol Infect Dis 6.

4. Purvish MP, Pankaj MS, Lalit KJE (2003) Hematopoetic stem cell transplantation in India. 50 Years of cancer control in India 136-149.

5. Shah AC, Karanwal A, Desai M (2015) Hematopoietic stem-cell transplantation in the developing world: Experience from a center in western India. J Oncol 9.

6. Basak J, Bhattacharyya D, Chakraborty (2012) A stem cell transplant: An experience from eastern India. Indian J Med Paediatr Oncol 33: 203-209.

7. Banavali DS (2009) Hematopoietic stem cell transplantation: Need for research \& potential applications. its status in India JSRM.

8. Dykewicz AC (2001) Hospital infection control in hematopoietic stem cell transplant recipients. Emerg Infect Dis.

9. Attal M, Harousseau JL, Stopa AM (1996) A prospective, randomosed trial of autologus bone marrow transplantation and chemotherapy in multiple myeloma. N Engl J Med 335: 91-97.

10. Child JA, Morgan GJ, Davis FE (2003) High dose chemotherapy with hematopoetic stem cell rescue for multiple myeloma. N Engl J Med 348: 1875-1883.
11. Kumar L, Raju GM, Ganessan K (2003) High dose chemotherapy followed by autologous hematopoetic stem cell transplant in multiple myeloma. Nat Med J India 16: 16-21.

12. Kumar L, Ghosh L, Ganessan P (2009) High dose chemotherapy with autologous stem cell transplantation for multiple myeloma experience from a developing country. BMT 43: 481-489.

13. Kayal S, Sharma A, Iqbal S (2014) High dose chemotherapy and autologous stem cell transplantation in multiple myeloma : A single institution experience at all India institute of medical sciences, New Delhi, using non-cryopreserved peripheral blood stem cells. Clin Lymph Myeloma Leukemia 14: 140-147.

14. Kumar L, Ganess P, Gogia A (2010) High dose chemotherapy with autologous stem cell transplantation for multiple myeloma: what predicts the outcome? Biol Blood Marrow Transplant 16: 239-240.

15. Philip T, Guglielmi C, Hagenbeek A (1995) Autologus bone marrow transplantation as compared with salvage chemotherapy in relapses of chemotherapy sensitive non hodgkins lymphoma. N Engl J Med 333 1540-1545.

16. Ladetto M, Marco FD, Benedetti F (2008) Prospective, multicenter randomized GITMO/IIL trial comparing intensive (R-HDS) versus conventional (CHOP-R) chemoimmunotherapy in high-risk follicular lymphoma at diagnosis the superior disease control of R-HDS does not translate into an overall survival advantage. 111: 4004-4013.

17. Kumar L, Ganessan P, Ghosh I (2010) Autologous blood stem cell transplantation for hodgkin and non-hodgkin lymphoma: complications and outcome. Natl Med J India 23: 6 .

18. Lazaurus HM, Hamadani M, Hari NP (2005) Autologous Stem Cell Transplantation. In: Devita H (eds) Rosenberg"s Cancer: Principles \& Practice of Oncology. 1907-1916.

19. Hermine O, Hoster E, Waleski J, Ribrag V, Brousse N, et al. (2012) Alternating courses of $3 \mathrm{xCHOP}$ and $3 \mathrm{xDHAP}$ plus rituximab followed by a high dose ARA-C containing myeloablative regimen and autologous stem cell transplantation (ASCT) increases overall survival when compared to 6 courses of $\mathrm{CHOP}$ plus rituximab followed by myeloablative radiochemotherapy and ASCT in mantle cell lymphoma: final analysis of the MCL younger trial of the European Mantle Cell Lymphoma Network (MCLnet). Blood (ASH Annual Meeting Abstracts) 623: 151 .

20. Gisselbrecht C, Glass B, Mounier N (2010) Salvage regimens with autologous transplantation for relapsed large B-cell lymphoma in the rituximab era. J Clin Oncol 28: 27.

21. Nair V, Sharma A, Mishra KD (2005) Stem cell transplantation: impact of high efficiency particulate air (HEPA) vs. non-HEPA bmt unit on transplant outcome: A single centre experience from India. Blood 106: 5322 . 
Citation: Raut SS (2017) Autologus Stem Cell Transplantation for Cancers: India: 2017. J Blood Disord Transfus 8: 379 . doi: 10.4172/2155-9864.1000379

Page 8 of 8

22. Prinja S, Kaur G, Malhotra P (2017) Cost-effectiveness of autologous stem cell treatment as compared to conventional chemotherapy for treatment of multiple myeloma in India. Indian J Hematol Blood Transfus 33: 31-40.

23. Raut S, Shah S, Shah K (2016) Improving outcome of hodgkins disease with autologous hematopoietic stem cell transplantation. Indian J Hematol Blood 32: 176-181.

24. Kumar L (2016) Autologous Stem Cell Transplantation for Multiple Myeloma: Long-Term Results. NatlMed J 29: 192-199.
25. Raut SS, Shah AS, Sharanangat VV (2015) Safety and efficacy of eltrombopag in post-hematopoietic stem cell transplantation (HSCT) thrombocytopenia Indian J Hematol Blood Transfus 31: 413-414.

26. Shah C, Karanwal A, Desai M, Shah D, Shah JR (2014) Autologus stem cell transplant in multiple myeloma: Excellent safety and efficacy possible in a non university hospital of developing country. J Hematol Thrombo Dis 2:148

27. Kumar L (2014) Complete response after autologous stem cell transplant in multiple myeloma. Cancer Med 3: 939-946. 